\title{
Acknowledgments
}

I acquired many debts in the course of writing this volume. By far the largest is owed to Hyman Kublin, my thesis adviser at the City University of New York, whose generous bestowal of wisdom and guidance was surpassed only by the boundless inspiration he imparted and concern he showed. I am also profoundly indebted to Arthur M. Schlesinger, Jr., whose careful reading of the manuscript produced numerous constructive suggestions, nearly all of which have been incorporated into the text. I would like to express my sincere appreciation, too, to Louis L. Snyder, Hans L. Trefousse and Telford Taylor. Certainly the work has benefited from their invaluable insight and selective criticism. Numerous individuals throughout the world, most of whom I have never met personally, assisted me in the locating of relevant materials. Nevertheless, a special note of gratitude here is owed to the published and other efforts of Frank Joseph Shulman, George C. Chalou, Robert Donihi and R. John Pritchard, as well as to the many helpful archivists and national librarians of the Allied nations and Japan. For her major contribution to the typing and re-typing of the manuscript, I am sincerely grateful to my sister, Marguerite. A particular debt, beyond words and measure, is owed to Sydney Rosenberg, who first showed me the way. Above all, I am most grateful to my parents, whose unfailing encouragement, patience and love sustained me throughout.

Such assistance notwithstanding, I alone, of course, am responsible for any shortcomings in this work. 


\section{A NOTE ON JAPANESE NAMES}

Japanese names throughout appear in Western style - that is, the personal names first, followed by the surname. 